\title{
The Supreme Court and deprivation of liberty: where are we now?
}

\section{Nick Brindle}

\begin{abstract}
SUMMARY
Deciding on where the tipping point between restrictions and deprivation arises in care settings has important legal implications, but until recently case law has not much helped to resolve these challenging issues. An important milestone has been the Supreme Court judgment in the so-called Cheshire West case. This judgment, handed down in March 2014, set a low threshold to apply (the 'acid test') in deciding when someone may be being deprived of their liberty and therefore that additional legal authorisation is required. The application of the acid test is not straightforward and its effects are wide-ranging. In this article, I discuss the evolution of the concept of deprivation of liberty in health and social care, the implications of the judgment and the application of the acid test. I also briefly highlight the interface between the Mental Capacity Act 2005 and the Mental Health Act 1983.
\end{abstract}

\section{LEARNING OBJECTIVES}

- Understand the details of the Supreme Court judgment in relation to the Cheshire West case

- Appreciate how this judgment has affected the threshold of what may be considered deprivation of liberty

- Appreciate the wide-ranging effects of this altered threshold in health and social care settings

\section{DECLARATION OF INTEREST}

None

'Deprivation of liberty' has been an elusive and ill-defined concept in health and social care settings. The words themselves are derived from Article 5 of the European Convention on Human Rights (ECHR), the right to liberty and security. In England and Wales, the Mental Capacity Act 2005 (MCA) authorises the restriction, but not the deprivation, of liberty of a person who lacks the relevant decision-making capacity. It is therefore necessary to distinguish the tipping point between permissible restrictions on liberty authorised under section 5 of the Act and an unlawful deprivation of liberty. The difference in law is very important, with significant implications if one gets it wrong. A deprivation of liberty without lawful justification and due legal process for scrutiny would be a breach of the person's rights under Article 5 of the ECHR, with associated consequences, including the right to compensation. In a recent judgment, Mr Justice Mostyn has referred to 'heavy damages claims (and lawyers' costs)' for cases that are found to be a deprivation of liberty (Bournemouth Borough Council v PS and DS [2015]).

The concept in health and social care has been poorly understood and underrecognised, and approaches used to identify deprivation of liberty have been shown to be unreliable (Cairns 2011). The judgment handed down by the Supreme Court in the so-called Cheshire West case $\left(P_{V}\right.$ Cheshire West and Chester Council and Anor and $P$ and $Q_{V}$ Surrey County Council [2014]) in March 2014 has established a threshold to apply and a measure of clarity as to when a deprivation of liberty may arise. This threshold is perhaps lower than many anticipated and as a consequence it has had wide-ranging effects. In this article I discuss the development of the concept of deprivation of liberty, the judgment itself and some of the implications.

\section{Evolution of the concept in health and social care}

The first point to note is that Article 5 of the ECHR is a 'limited right', not an 'absolute right', and it does not protect us from detention. There are defined circumstances when it does not apply. It expressly permits confinement of criminals and illegal immigrants, and the 'lawful detention of persons for the prevention of the spreading of infectious diseases, of persons of unsound mind, alcoholics or drug addicts or vagrants'. It does, however, protect us against 'arbitrary detention', so that deprivations are made in accordance with a procedure prescribed in law.

We turn then to the case of Mr L, a man with autism and severe intellectual disabilities cared for in Bournewood Hospital (HL $v$ United Kingdom [2004]). The facts of his case are well-known and will not be repeated here, ${ }^{\dagger}$ but ultimately two important issues were raised. First, was Mr L deprived of his liberty? The highest UK appellate court, the House of Lords (now the Supreme

\section{ARTICLE}

Nick Brindle is a consultant in old age psychiatry with Leeds and York Partnership NHS Foundation Trust and an established member of a team delivering training in mental health law for the Andrew Sims Centre, Leeds. Correspondence Dr Nick Brindle, The Mount, 44 Hyde Terrace, Leeds LS2 9LN, UK. Email: nbrindle@ nhs.net

${ }^{\dagger}$ For an outline, see Brindle N, Branton T (2010) Interface between the Mental Health Act and Mental Capacity Act: deprivation of liberty safeguards. Advances in Psychiatric Treatment, 16: 430-7. Ed. 
Court), found that he was not. But the European Court of Human Rights (ECtHR) overturned this decision, determining that Mr L was deprived of his liberty, because clinicians took 'complete and effective control over his care and movements' and he was not 'free to leave'. The second issue was whether or not the common law (judge-made law rather than that enshrined in statute) was sufficient authority for the deprivation. The ECtHR judgment was that common law was not compliant with Article 5 because it is not a 'procedure prescribed by law'.

\section{The Bournewood gap and DoLS}

The Mental Health Act 1983 (MHA) provides the required legal mechanisms for authorising the deprivation of liberty of patients detained under the Act. However, it was not generally used for patients with long-term incapacity such as dementia or intellectual disability, particularly if they were compliant with the admission to hospital, as was Mr L. Thereafter, the 'Bournewood gap' was recognised: this referred to the legal predicament of the tens of thousands of people who lacked capacity to consent to admission to psychiatric hospitals and who were deprived of their liberty but without the protection of the law. This, of course, also applied in social care settings such as care homes. The government (in England and Wales) had to plug the legal gap left in the wake of the ECtHR ruling and, although different options were considered (Department of Health 2005), it introduced the Deprivation of Liberty Safeguards (DoLS) to the MCA (via the 2007 amendments to the MHA).

\section{Defining and identifying deprivation of liberty}

The concept of deprivation of liberty is at the heart of the DoLS, but there is a distinct lack of guidance on what it is. Detention and deprivation are not defined in the ECHR and, although many bodies and organisations, including parliament's own Joint Committee on Human Rights (2007), proposed that a statutory definition be adopted, this was rejected by the government, which sought to rely on the emergence of relevant case law. The approach meant that there was a dearth of clarity and it perpetuated a state of affairs that seemed to be as perplexing for judges and lawyers as for practitioners, including clinicians and social workers.

The courts, in trying to provide guidance on the limits of permissible restrictions, had to apply certain principles and characteristics of deprivation of liberty derived from domestic and ECtHR cases. For example, it was recognised that depriving as opposed to restricting someone's liberty 'is merely one of degree or intensity and not one of nature or substance' and account must be taken 'of a whole range of factors arising in a particular case such as the type, duration, effects and manner of implementation of the measure in question' (Guzzardi v Italy (1980)). Judicial interpretation of Article 5 of the ECHR in the domains of health, social care and beyond has relied on an analysis of the 'concrete circumstances' (JE $V$ DE and Surrey County Council [2006]) of the case. The sensitive nature of cases before the courts meant that considerations were not readily generalisable; judgments often appeared contradictory or introduced concepts that had limited relevance in day-to-day practice. Practical advice on identifying or avoiding deprivation of liberty in the DoLS Code of Practice (Ministry of Justice 2008) states that one should always consider 'all the circumstances of each and every case' and the Code includes a list of factors that have been taken into account by the European and domestic courts. The Code also points out that these are merely factors to consider and not conclusive on their own. Because each case had to be assessed on its own merits, considerable variation in practice arose among practitioners and clinicians (Care Quality Commission 2015).

\section{The Supreme Court and Cheshire West}

This uncertainty about what constitutes deprivation of liberty has, to some degree, been diminished following a Supreme Court judgment handed down in March 2014. The case (which has come to be known as Cheshire West) concerned three individuals, two sisters who had been taken into care $(\mathrm{P}$ and $\mathrm{Q})$ and a man $(\mathrm{P})$, all with severe disabilities. Lady Hale in her opening statement made it clear what the Court had to decide: 'whether the living arrangements made for a mentally incapacitated person amount to a deprivation of liberty. If they do, then the deprivation has to be authorised, either by a court or by the procedures known as the deprivation of liberty safeguards' ( $P{ }_{V}$ Cheshire West and Chester Council and Anor and $P$ and $Q v$ Surrey County Council [2014]). To understand the judgment it is helpful briefly to consider the circumstances of the three individuals.

\section{$P$ and 0}

Born in 1991 and 1992, P and Q (initially referred to as MIG and MEG in the Court of Protection) are sisters both with intellectual disabilities who lived with their mother, along with their sister and halfsister, until April 2007 when they were removed. 
The life of $\mathrm{P}$ and $\mathrm{Q}$ in the family home was described in the judgment of the Court of Appeal (Re $P$ and $Q$ (2011)) as 'dysfunctional and abusive'. The severity of their impairments meant that at the time both $\mathrm{P}$ and $\mathrm{Q}$ lacked capacity to make decisions in relation to their care and residency. They required a high degree of supervision in their respective environments and they had no safety awareness. The individual features of $\mathrm{P}$ and $\mathrm{Q}$ are summarised in Box 1. The judge in the Court of Protection, Mrs Justice Parker, found that there was no deprivation of liberty of either girl (Re MIG and MEG [2010]). To clarify the law, the case was appealed. The Court of Appeal agreed and the 'relative normality' of the living arrangements was highlighted, along with the social, recreational and educational opportunities available to them both.

\section{$P$ (in Cheshire West)}

When his case first came before the Court of Protection, $\mathrm{P}$ (now often identified as $\mathrm{P}$ (in Cheshire West) was 38 years old. He was born with cerebral palsy and Down syndrome with significant physical and intellectual disabilities and he had a history of cerebrovascular accidents. He required around the clock care to meet his substantial personal needs. Importantly, he had marked communication difficulties; he needed prompts and significant help with activities of daily living and wore incontinence pads. To prevent him from putting pieces of faecally contaminated pads in his mouth staff had to resort to dressing him in a body suit of all-in-one underwear. He was not prescribed any medication. Further details are summarised in Box 2.

In the Court of Protection it was successfully argued that $\mathrm{P}$ was deprived of his liberty (Cheshire West and Chester Council v P [2011] EWHC 1330 COP). There was a requirement for intrusive physical interventions and restraint; also the degree of monitoring of P's life amounted to 'complete and effective control' over his care and movements, along with his lack of freedom to leave the premises unescorted.

The judgment was again appealed. In the Court of Appeal it was decided that $\mathrm{P}$ was not deprived of his liberty (Cheshire West and Chester Council V $P$ [2011] EWCA Civ 1257). In his judgment, Lord Justice Munby made the observation that "because of his disabilities, $\mathrm{P}$ was inherently restricted in the kind of life he can lead'. Furthermore, he introduced the notion of the 'relevant comparator': when interpreting the "normality' of a setting, the relevant comparator is 'an adult of similar age with the same capabilities as X, affected by the same condition or suffering the same inherent mental
BOX 1 The situation of $\mathrm{P}$ and $\mathrm{O}$

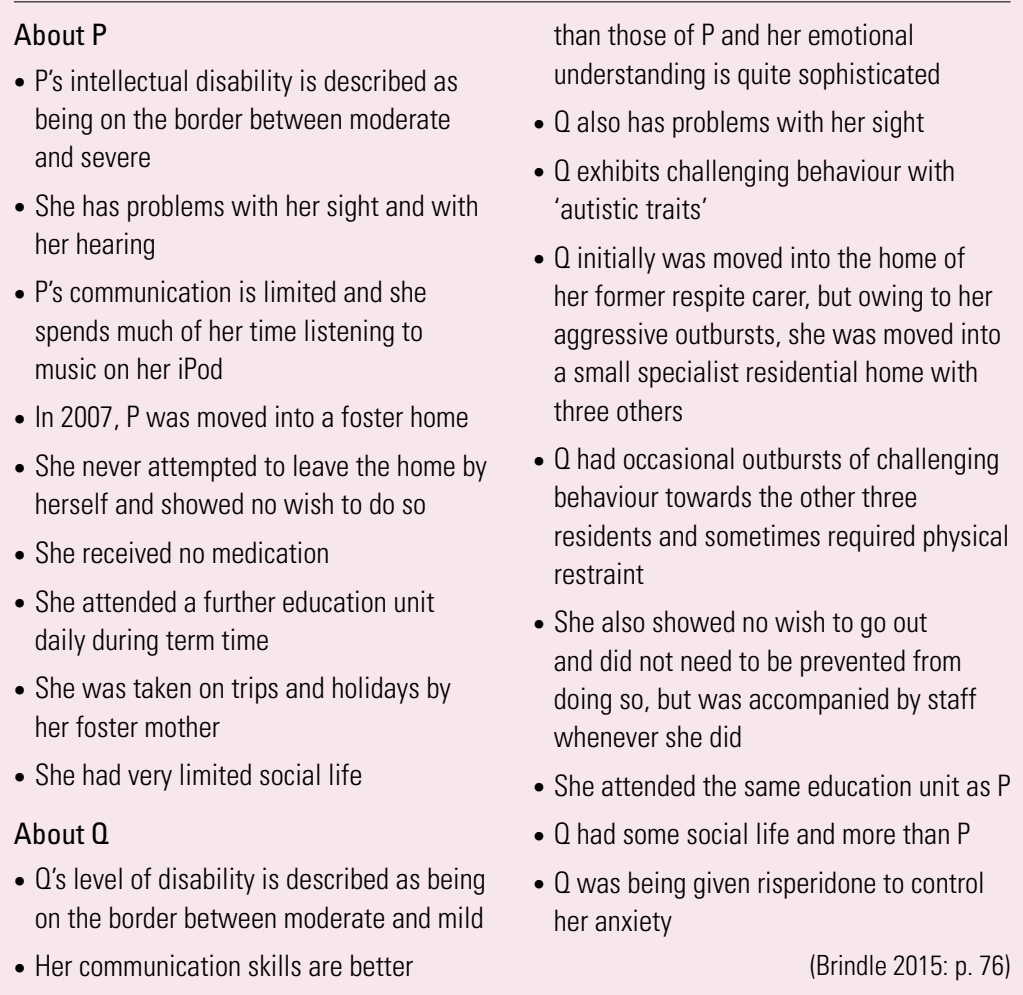

and physical disabilities and limitations [...] as X' and not the normality of 'the life of the able-bodied man or woman on the Clapham omnibus'. This was a hugely significant and contentious judgment that raised more questions than it answered.

B0X 2 The situation of $\mathrm{P}$ (in Cheshire West)

- $P$ lived with his mother until the age of 37

- P's mother developed health problems and in November 2009 he was moved under the authority of an order of the Court of Protection to Z House

- Z House is described as a spacious bungalow, with a cosy and pleasant atmosphere, which $P$ shared with two other residents

- There are two staff on duty during the day and one waking member overnight

- $P$ received significant additional one-to-one support to help him leave the house whenever he chose

- He attended a day centre four days a week and hydrotherapy on the fifth day

- P also went to a club, pub and the shops and he regularly saw his mother, who lived close to his bungalow

- He could walk for short distances but needed a wheelchair to go further

(Brindle 2015: p. 77) 


\section{The Supreme Court judgment}

When the two cases were brought before the Supreme Court, the majority decision of the Court was that all three individuals were deprived of their liberty $\left(P_{V}\right.$ Cheshire West and Chester Council and Anor and $P$ and $Q v$ Surrey County Council [2014]). Taking the lead, Lady Hale emphasised that the rights in the ECHR apply to everyone and underpin the UN Convention of the Rights of Persons with Disabilities (UNCRPD). She made it clear that if it would be a deprivation of my liberty to be obliged to live in a particular place, subject to constant monitoring and control, only allowed out with close supervision, and unable to move away without permission even if such an opportunity became available, then it must also be a deprivation of the liberty of a disabled person'.

Also, these conditions apply whatever the circumstances or characteristics of the living arrangements, even if they 'are comfortable, and indeed make my life as enjoyable as it could possibly be'. Other factors that Lady Hale considered not relevant were the person's compliance or lack of objection; the relative normality of the placement (whatever the comparison made); and the reason or purpose behind a particular placement.

Lady Hale asked the question: 'Is there an acid test for the deprivation of liberty in these cases?' and answered it in the following way: 'if the acid test is whether a person is under the complete supervision and control of those caring for her and is not free to leave the place where she lives, then the truth is that both MIG and MEG are being deprived of their liberty. Furthermore, that deprivation is the responsibility of the state'.

As we can see, the language is largely unchanged between this judgment and that in $H L$ (and all relevant judgments in between) and it introduces what amounts to a low threshold of transition between restriction and deprivation of liberty. This assumption of a low threshold to be adopted is reinforced by the following statement by Lady Hale: 'Because of the extreme vulnerability of people like P, MIG and MEG, I believe that we should err on the side of caution in deciding what constitutes a deprivation of liberty in their case'. In the same judgment, Lord Neuberger drew attention to the 'area and period of confinement', suggesting that the location and duration of restrictions are important considerations.

\section{Implications of the acid test}

The effect of the Cheshire West Supreme Court judgment and application of the acid test is to increase hugely the number of people who might be considered to be deprived of their liberty and whose care therefore requires additional legal authorisation. This will apply to the broad range of settings, not just hospitals and care homes, in which the MHA or DoLS might apply. There are many people outside the scope of DoLS whose deprivation of liberty requires court authorisation, for example those in supported living and residential schools or colleges. In the Supreme Court, Lords Hodge and Carnwath (who were dissenting in relation to $\mathrm{P}$ and $\mathrm{Q}$ ) were 'concerned that nobody using ordinary language would describe people living happily in a domestic setting as being deprived of their liberty' $\left(P_{V}\right.$ Cheshire West and Chester Council and Anor and $P$ and $Q v$ Surrey County Council [2014]). However, there will also be those aged 16 and over being cared for in a family home (whether by relatives, foster carers or other arrangements), but with a sufficient degree of state involvement to engage Article 5 and whose deprivation therefore requires court authorisation. In some circumstances there has also been a need for local authorities to revisit previous decisionmaking in relation to deprivation of liberty.

The acid test is not as clear as it might at first seem. It is not possible to say for certain what the terms 'continuous supervision and control' and 'not free to leave' mean, and in practice they have provoked considerable debate. It is clear, however, that 'continuous' does not have to mean uninterrupted and 'not free to leave' means that the individual need not necessarily express a desire to do so but would be stopped if they tried. It is unlikely that a more precise definition will arise imminently and, anecdotally, there seems to be little standardisation. Although deliberations will need to reflect the overall effects and consequences on the person's life, in reality there is marked variation in interpretation and practice and this is perhaps reflected in the wide variation of referrals across England and Wales. Such variation is understandable given $\mathrm{Mr}$ Justice Mostyn's recognition of 'how difficult it is to pin down what is a deprivation of liberty (i.e. detention by the state) as opposed to a restriction on movement or nothing beyond humane and empathetic care' (Bournemouth Borough Council v PS \& DS [2015]).

\section{The acid test in psychiatric settings}

For psychiatrists, the Cheshire West judgment draws further attention to the interface between the MHA and DoLS. Determining the appropriate basis for authorising admission and treatment for mental disorder can raise difficult questions. In an earlier Upper Tribunal case, Mr Justice Charles highlighted some of the difficulties: 
'All decision makers who have to address the application of the provisions of the DOLS contained in Schedules A1 and 1A of the MCA are faced with complicated legislative provisions and their difficulties are compounded when they have to consider the relationship between the MHA and the MCA. Regular visitors to the provisions need to remember the daunting task they set for lawyers and non-lawyers who have to apply them' ( $A M \mathrm{~V}$ (1) South London 8 Maudsley NHS Foundation Trust and (2) The Secretary of State for Health [2013]).

It is fair to say that the complexity of Schedule 1A (which sets out how to determine whether an individual is 'ineligible' to be deprived of their liberty by the MCA) is now infamous, notwithstanding that the revised MHA Code of Practice (Department of Health 2015a) offers some guiding principles in relation to which act to use for both physical and mental disorders, and reflects this judgment and further developments in case law. I refer readers to the Code of Practice for further details, but the influence of the Supreme Court judgment in Cheshire West can be seen, for example, in the statement that: 'a person who lacks capacity to consent to being accommodated in hospital for care and/or treatment for mental disorder and who is likely to be deprived of their liberty should never be informally admitted to hospital (whether they are content to be admitted or not)' (para. 13.53).

At the time of writing, there are no national figures available to indicate whether there has been a direct effect on the behaviour of psychiatrists and approved mental health professionals or the number of detentions under the MHA as a result of the Supreme Court judgment. In my own locality we have observed a $10-15 \%$ increase in detentions under the MHA since the judgment, with a parallel reduction in informal admissions which, given the timing and population, is almost certainly due to the judgment. We will need to await the emergence of more precise data from the Care Quality Commission before coming to any firm conclusions.

The implications of the judgment and the above statement from the MHA Code of Practice suggest that there is limited scope for informal admission of incapacitous individuals. The revised Code of Practice instructs us that 'if the MCA can be used safely and effectively to assess or treat a patient, it is likely to be difficult to demonstrate that criteria for detaining the patient under the [MHA] are met' (para. 14.23). Unless the patient is as free from restrictions as any capacitous individual, their admission and treatment will likely require additional legal authorisation.

\section{The acid test in social care settings}

In social care, the impact of the acid test on the number of individuals (for example those who have dementia or intellectual disabilities in care homes or other residential settings) who are now deemed to be deprived of their liberty has been overwhelming. This is not to suggest that the care of these residents has become more restrictive or indeed has changed at all. In the 6 months following the Cheshire West judgment there was a ninefold increase in the number of applications for DoLS (Association of Directors of Adult Social Services 2014). The enormous pressure on local authority DoLS teams and on the workload of best interests assessors is reflected in the failure to meet statutory timescales in around half of cases (McNicholl 2014). Although historically there have been wide geographic variations in the numbers of applications, and this continues, at the end of September 2014, there were 19429 applications pending a decision (Care Quality Commission 2015). The knock on effects are the increased burden on care providers, who require the security of knowing that the care they are delivering is scrutinised, lawful and appropriately authorised (Care Quality Commission 2015) and on the capacity of the Care Quality Commission to monitor and enforce the safeguards.

The implications on workforce and other resources regarding the availability of assessors and independent mental capacity advocates are huge. Given the very large numbers of assessments and authorisations taking place, one has to wonder whether their quality, and therefore the protections offered by the DoLS for these vulnerable adults, is being maintained. Furthermore, the anticipated costs of the projected tenfold increase in deprivation of liberty cases (from 10184 in 2013-2014 to over 100000 in 2014-2015) is estimated to be at least $£ 45$ million, excluding legal costs (McNicholl 2014) with the total bill, covering all councils in England and Wales, predicted to exceed $£ 70$ million. This does not include the additional financial burden of aftercare under section 117 of the MHA if the numbers of people detained under section 3 of the Act increases. A one-off contribution of $£ 25$ million for local authorities has been announced this year but this will not go far in addressing the bureaucratic burden and escalating costs that have had to be met within existing budgets and at a time when there is the additional responsibility on local authorities to implement the Care Act 2014.

\section{The acid test in general hospitals}

The judgment in Cheshire West potentially makes for very significant problems in general hospitals. In acute hospital settings there are inevitably large numbers of patients who lack the capacity 
to consent to their care or treatment, and rigid application of the acid test means that many may be deprived of their liberty. This needs legal authorisation. For patients whose lack of capacity is due to such mental disorders as delirium or dementia, the MHA or DoLS could be used. If the lack of capacity is not due to mental disorder, for example if the person is unconscious, then the authority for their detention, if authority is required, would need to come from the Court of Protection.

The processes of DoLS authorisation do not lend themselves to many circumstances in general hospitals and the practicalities of seeking court orders in the vast array of other situations are unworkable. Despite attempts, in many instances, to embed the principles of the MCA and DoLS into the clinical practice of general hospitals, there are clearly shortfalls which derive in part from the cumbersome nature of the processes. There are also situations in which subjecting families and patients to additional assessments to fulfil legal requirements may cause distress for no obvious benefit, for example for patients in a coma or in palliative care.

In January 2015, the Department of Health issued limited guidance on the application of the acid test in palliative care (Department of Health $2015 \mathrm{~b})$. This gives some further clarification of the concepts of 'free to leave' and 'continuous supervision and control' and might have additional application in other general hospital settings. However, there again seem to be wide variations in how this issue is dealt with. Difficult questions arise. For example, does ignoring the legal issue relieve the dying of an unnecessary burden or deprive them of their basic legal rights? In April 2015, the Law Society published helpful and comprehensive guidance regarding deprivation of liberty in general hospitals, hospices and a range of other situations.

\section{Implications of the Cheshire West judgment for children}

In the Supreme Court judgment Lord Neuberger addressed the position in relation to children in the following way. He stated that the ordinary family set-up will not engage Article 5 of the ECHR because there is no state involvement. However, where a child is looked after by foster parents, it is the state's involvement in placing the child that may engage Article 5 and there may be a deprivation of liberty. Further to this, there may be some cases where the state may be under a positive obligation to bring abnormal restrictions on a child's liberty to an end even when these are imposed in a private home. Therefore, if a child is to be deprived of their liberty and the state is responsible, and if the child is not competent to consent, the deprivation will have to be authorised. The choice of legal scheme, for example the Children Act 1989 or the MHA (note that DoLS authorisations apply only to those aged 18 or over), and the process can be complex and will depend on the purpose of the detention and the facts of the case.

Further guidance can be derived from the MHA Code of Practice (Department of Health 2015a), but if there is any doubt it is best to seek appropriate legal advice.

\section{Conclusions}

The test for deprivation of liberty is now clearer than before, although the legal landscape is not yet stable. Mr Justice Mostyn took up on the arguments of the dissenting Law Lords in Cheshire West in deciding that the care of a 52-year-old disabled woman in her own home did not amount to deprivation of her liberty (Rochdale $M B C{ } \mathrm{KW}$ [2014]). Although an appeal was allowed there was no hearing, which meant that an opportunity to clarify the legal situation further was perhaps missed. This is one of a series of four judgments in which Mr Justice Mostyn has been critical of the Supreme Court judgment and reiterated his view that it is an issue that should be urgently reconsidered by the Supreme Court (the other three cases are London Borough of Tower Hamlets v TB \& Anor [2014]; Bournemouth Borough Council ${ }_{v} P S$ and DS [2015]; Rochdale Metropolitan Borough Council v KW \& Ors [2015]). Therefore, while judges continue to disagree and individuals agonise over the wording, differences in the interpretation of 'continuous supervision and control' and 'free to leave' will inevitably persist.

The Supreme Court judgment in Cheshire West arrived just days after the Select Committee on the Mental Capacity Act 2005 published its postlegislative report (SCMCA 2014). Some of the key findings of the report concerned the DoLS. The Committee found that the evidence suggests that tens of thousands of people were being deprived of their liberty without the protection of the law and that 'the Government needs to go back to the drawing board to draft replacement provisions that are easy to understand and implement, and in keeping with the style and ethos of the Mental Capacity Act' (House of Lords 2014). It recommended that a new system should extend to cover people in supported living arrangements. The Committee recommended that the Law Commission considers how deprivation of liberty should be authorised and supervised in hospitals, 
care homes and community settings. At the time of writing, the Law Commission is projected to publish its report and recommendations in summer 2016.

Meanwhile, the overwhelming burden on supervisory bodies in meeting the statutory requirements for assessments and authorisations in relation to DoLS will remain undiminished. In the resultant balancing of budgets, other services and responsibilities will necessarily suffer. The pressures in health and social care are likely to escalate with increasing scrutiny from the Care Quality Commission, together with the peril of court proceedings and compensation for unauthorised deprivations. There is a huge responsibility placed on local authorities in making sure that those deprived of their liberty are afforded effective access to the Court of Protection so as to secure their rights under the ECHR. More recent case law continues to highlight the difficulties and complexities that local authorities face in carrying out their duties (Re AJ (Deprivation of Liberty Safeguards) [2015]). Attempts to streamline the processes of the Court of Protection to cope with the anticipated large increase in applications are in a state of evolution (Re $X$ and Ors (Deprivation of Liberty) [2014]). For clinicians, including psychiatrists, the decision as to whether any individual is deprived of their liberty is, thankfully, not theirs to make. Nevertheless, clinicians must be able to recognise when deprivation of liberty might occur and be sensitive to the distinction between restriction and deprivation of liberty, particularly where restrictions are complete and a deprivation can happen very quickly (ZH (by his Litigation Friend) v Metropolitan Police Commissioner [2012]).

Clinicians should be apprised of legal developments and know how to respond appropriately in order that care is lawfully delivered. Although there is statutory guidance in the form of the Codes of Practice, it is likely that practice will be enhanced when supported by local policies and procedures. Online training for medical assessors who are required to conduct the sometimes legally complex eligibility assessments for the DoLS process is being revised to reflect legal developments, and enhanced training across the board has been called for in relation to the MCA (SCMCA 2014).

The Supreme Court judgment in Cheshire West is a milestone in health and social care, but nonetheless it has provoked a measure of chaos. However, one must not lose sight of the requirement to protect the most vulnerable of individuals, given that the decision-making can go badly wrong (Hillingdon v Steven Neary [2011]; A Local Authority v Mrs D and Anor [2013]). The shifting sands of the legal developments will continue to have a bearing on practice and resources in health and social care and, although improvements will not be fast approaching, one can only hope that the Law Commission recommendations are both practical and effective.

\section{Acknowledgements}

Thanks to Ben Alderson, Tony Zigmond and Christian Walsh for helpful comments in preparation of this manuscript.

\section{References}

Association of Directors of Adult Social Services (2014) Number of DoLS referrals rise tenfold since Supreme Court ruling (6 June). ADASS (http:// www.adass.org.uk/number-of-dols-referrals-rise-tenfold-since-supremecourt-ruling-jun-14). Accessed 27 Aug 2015.

Brindle N, Branton T, Stansfield A, et al (2015) A Clinician's Brief Guide to the Mental Capacity Act (2nd edn). RCPsych Publications.

Cairns R, Brown P, Grant-Peterkin H, et al (2011) Judgements about deprivation of liberty made by various professionals: comparison study. Psychiatrist, 35: 344-9

Care Quality Commission (2015) Monitoring the Use of the Mental Capacity Act Deprivation of Liberty Safeguards 2013/14. COC.

Department of Health (2005) 'Bournewood' Consultation: The Approach to be Taken in Response to the European Court of Human Rights in the 'Bournewood' Case. Department of Health.

Department of Health (2015a) Mental Health Act 1983: Code of Practice. TSO (The Stationery Office)

Department of Health (2015b) Letter to MCA-DoLS leads in local authorities and the NHS. Department of Health (http://www. mentalcapacitylawandpolicy.org.uk/wp-content/uploads/2014/04/DHLetter-to-MCA-DoLS-Leads-14-January-2015-FINAL.pdf).

House of Lords (2014) The Mental Capacity Act is failing, says Lords. Parliamentary Business, 13 March.

Joint Committee on Human Rights (2007) Legislative Scrutiny: Mental Health Bill. Fourth Report of Session 2006-07. TSO (The Stationery Office) (http://www.publications.parliament.uk/pa/jt200607/jtselect/ jtrights/40/40.pdf).

Law Society (2015) Identifying a Deprivation of Liberty: A Practical Guide. Law Society.

McNicholl A (2014) Half of Deprivation of Liberty Safeguards cases breaching legal timescales. Community Care (http://www.communitycare. co.uk/2014/10/01/50-deprivation-liberty-safeguards-cases-breachinglegal-timescales).

Ministry of Justice (2008) Mental Capacity Act 2005: Deprivation of Liberty Safeguards. Code of Practice to Supplement the Main Mental Capacity Act. TSO (The Stationery Office).

Select Committee on the Mental Capacity Act 2005 (2014) Mental Capacity Act 2005: Post-Legislative Scrutiny. TSO (The Stationery Office) (http://www.publications.parliament.uk/pa/ld201314/Idselect/ Idmentalcap/139/139.pdf).

\section{Cases}

A Local Authority v Mrs D and Anor [2013] EWCOP B34.

AM v (1) South London \& Maudsley NHS Foundation Trust and (2) The Secretary of State for Health [2013] UKUT 0365 (AAC)

Bournemouth Borough Council v PS and DS [2015] EWCOP 39.

Cheshire West and Chester Council v P [2011] EWHC 1330 (COP).
MCO answers

$1 d \quad 2 d \quad 3 b \quad 4 c \quad 5 b$ 
Cheshire West and Chester Council v P [2011] EWCA Civ 1257

Guzzardi v Italy 7367/76 (1980) ECHR 5

Hillingdon v Steven Neary [2011] EWHC 1377 (COP).

HL v United Kingdom [2004] 40 EHRR 761.

JE v DE and Surrey County Council [2006] EWHC 3459 (Fam).

London Borough of Tower Hamlets v TB \& Another [2014] EWCOP 53.

$P v$ Cheshire West and Chester Council and Anor and P and $Q v$ Surrey County Council[2014] UKSC 19
Re AJ (Deprivation of Liberty Safeguards) [2015] EWCOP 5

Re MIG and MEG [2010] EWHC 785 (Fam).

Re $P$ and $Q ; P$ and $Q v$ Surrey County Council; sub nom Re MIG and MEG (2011) EWCA Civ 190

Re $X$ and Ors (Deprivation of Liberty) [2014] EWCOP 25; EWCOP 37.

Rochdale MBC v KW[2014] EWCOP 45

Rochdale Metropolitan Borough Council v KW \& Ors [2015] EWCOP 13

ZH (by his Litigation Friend) v Metropolitan Police Commissioner [2012] All ER (D) 134 (Mar).

\section{MCOs}

Select the single best option for each question stem

1 For a person who lacks capacity, relevant considerations when deciding whether their placement amounts to a deprivation of their liberty include:

a the person's lack of objection

b the relative 'normality' of the placement

c the reason or purpose behind a particular placement

$\mathrm{d}$ how long the placement is likely to last

e the limited circumstances of the individual case.

2 In relation to Article 5 (the right to liberty and security) of the ECHR:

a it is an absolute right under the ECHR

$\mathrm{b}$ it prohibits confinement of individuals in all circumstances

c common law powers are compliant with Article 5 of the ECHR

$d$ the legal authority to deprive someone of their liberty requires a procedure prescribed by law e deprivation of liberty is defined in the ECHR.
3 In the Supreme Court judgment regarding $\mathrm{P}$ and $\mathrm{Q}$ and $\mathrm{P}$ in Cheshire West, the 'acid test':

a applies only to hospitals and care homes

b applies only if there is state involvement in the care

c provides a clear objective test for what constitutes a deprivation of a person's liberty

$d$ does not apply in end-of-life situations

e relates only to the person's freedom to leave.

4 Which of the following statements is true?

a the concept of deprivation of liberty is now fixed

b the state cannot be responsible for restriction imposed on a child looked after by foster parents

c the state may be under a positive obligation to intervene with restrictions imposed in a private home

d the DoLS scheme can now apply to children under the age of 18

e the MHA cannot be used to authorise the deprivation of liberty of a minor.

\section{In relation to detention under the Mental} Health Act 1983:

a the revised MHA Code of Practice does not reflect the judgment of the Supreme Court in Cheshire West

b the MHA forbids the informal admission of patients who lack capacity into circumstances that amount to a deprivation of their liberty

c as a result of the Supreme Court judgment in Cheshire West the number of detentions under the MHA is likely to decrease

$\mathrm{d}$ no guidance is available in relation to the choice of which legislation (MHA or DoLS) to use to deprive someone of their liberty in different settings

e Schedule A1 of the MCA sets out where the MHA rather than DoLS must be used. 